\title{
Serum concentrations of proinflammatory cytokines in Graves' disease: effect of treatment, thyroid function, ophthalmopathy and cigarette smoking
}

\author{
Mario Salvi, Mario Pedrazzoni, Giuseppe Girasole, Nicola Giuliani, Roberta Minelli, Jack R Wall ${ }^{1}$ and Elio Roti \\ Centro per lo Studio, Prevenzione, Diagnosi e Cura delle Tireopatie, Istituto di Clinica Medica Generale, Università degli Studi di Parma, Parma, \\ Italy and ${ }^{1}$ Division of Endocrinology and Metabolism, Dalhousie University, Halifax, Nova Scotia, Canada \\ (Correspondence should be addressed to M Salvi, Cattedra di Endocrinologia, Università di Parma, via Gramsci 14, 43100 Parma, Italy)
}

\begin{abstract}
Objective: In the present study we have measured the concentrations of interleukin-6 (IL-6), soluble IL6 receptor (sIL-6R), tumor necrosis factor- $\alpha$ (TNF- $\alpha$ ), interleukin-1 $\beta$ (IL-1 $\beta$ ) and IL-1 receptor antagonist (IL-1Ra) in the serum of patients with Graves' disease (GD). By multivariate analysis, we have evaluated the effect of antithyroid treatment, thyroid function, the presence or absence of active thyroid-associated ophthalmopathy (TAO), the patient's smoking habits and the relation to circulating anti-thyrotropin (TSH) receptor (TRAb) and anti-thyroperoxidase antibodies (TPOAb).

Subjects: We studied 84 GD patients, 51 untreated and 33 receiving methimazole (MMI) therapy. Twenty-three $(45 \%)$ untreated patients and $18(54 \%)$ patients on MMI had active TAO. We also studied 67 normal subjects as controls. Thirty-one GD patients (43\%) and 16 controls (36\%) were smokers. Results: Serum IL-6 concentrations were significantly higher in both untreated patients $(P<0.001)$ and treated patients $(P<0.006)$, when compared with controls. Serum sIL-6R concentrations were significantly affected by treatment $(P=0.001)$. Serum IL-1Ra concentrations were not different in GD patients, whether treated or untreated, compared with controls. Serum IL-6 concentrations were not influenced by thyroid function and there was a significant interaction between treatment and the presence of active TAO $(P=0.003)$. In hyperthyroid patients with active TAO serum, sIL-6R concentrations were significantly higher than in those with inactive TAO $(P=0.003)$. In untreated GD patients there was no significant effect of thyroid function and TAO activity on the serum concentrations of TNF- $\alpha$ and IL-1 $\beta$. Serum IL-1Ra concentrations were not affected by the presence of TAO. Smoking had no effect on serum IL-6, sIL-6R, TNF- $\alpha$, IL-1 $\beta$ and IL-1Ra concentrations, even in the presence of an active TAO. Serum concentrations of IL- 6 , sIL-6R, TNF- $\alpha$ and IL- $1 \beta$ and IL-1Ra were not different in patients with and without TRAb or TPOAb, in relation to either thyroid function, TAO activity or smoking.

Conclusions: Our work shows that: (i) the proinflammatory cytokine pattern in GD is greatly influenced by antithyroid drug treatment; (ii) the increased circulating IL-6/sIL-6R concentrations observed in patients with active TAO may derive from the activation of humoral reactions in sites other than the thyroid; and, (iii) cigarette smoking has no effect on serum IL-1/IL-1Ra concentrations in TAO.
\end{abstract}

European Journal of Endocrinology 143 197-202

\section{Introduction}

The acute phase response to inflammation is characterized by the combination of hepatocyte-derived plasma proteins induced by the inflammatory cytokines tumor necrosis factor- $\alpha$ (TNF- $\alpha$ ) and interleukin-1 (IL-1)- $\beta$ and those induced by interleukin- 6 (IL-6) (1). The biological action of IL- 6 results from direct binding of the soluble IL-6 receptor/IL-6 complex (sIL-6R/IL-6) to gp130, the protein which transduces the IL-6 signal $(2,3)$. TNF- $\alpha$ is produced by macrophages and T-cells in response to bacteria, viruses and cytokines, and is also a powerful modulator of the immune response, mediating the induction of adhesion molecules and other cytokines. IL-1 derives mainly from macrophages and exists in two forms, namely IL- $1 \alpha$ and IL- $1 \beta$, which bind to the same receptor. In humans, most of the IL-1 activity found in the circulation is from IL-1 $\beta$ (4). Proinflammatory effects of IL- 1 are counterbalanced by the IL-1 receptor antagonist (IL-1Ra) which is structurally related and competitively binds to the IL-1 receptor, inhibiting the biological response. Tissue hypoxia, such as that induced by cigarette smoking, has been reported to increase production of IL-1 $(5,6)$ 
or reduce that of IL-1Ra $(7,8)$ and influence other cytokines, including IL-6 (9-12).

In previous studies, markedly elevated serum concentrations of IL- 6 were found in patients with thyrotoxicosis characterized by destructive inflammatory processes $(13,14)$. We have recently reported increased serum IL- 6 concentrations in patients with hyperthyroidism from Graves' disease (GD) (15), while others have found elevated IL-6 concentrations in patients with hyperthyroid GD and toxic nodular goiter, but increased TNF- $\alpha$ only in GD $(16,17)$. By using a 'high sensitivity' immunoassay, we have also found increased concentrations of sIL-6R in the serum of patients with hyperthyroid GD in the presence of active thyroid-associated ophthalmopathy (TAO) (15). Recent studies from Tan et al. (18) and Heufelder \& Bahn (19) have demonstrated a role for IL-1 and IL-1Ra in the pathogenesis of TAO; they have hypothesized that the detrimental effect of cigarette smoking may be mediated by reduced inhibition of IL-1Ra on IL-1 stimulation (20). To date, however, most of the studies on the serological patterns of proinflammatory cytokines in GD and TAO have produced conflicting results, perhaps due to the different methods of measurement employed (21). In fact, it is still unclear whether serum cytokine concentrations in GD are influenced by thyroid function or by autoimmune reactions $(16,17,22)$. In addition, other factors like antithyroid therapy, activity of TAO and age may have different effects on circulating cytokines.

The aims of the present study were: (i) to measure the concentrations of IL- 6 and sIL-6R in the serum of patients with GD in relation to those of other proinflammatory cytokines, such as TNF- $\alpha$, IL- $1 \beta$. and IL-1Ra; and, (ii) to evaluate the effect on the cytokines of age, antithyroid treatment, thyroid function, the presence or absence of active TAO and the patient's smoking habits by multivariate analysis (which best suits the study of such a heterogeneous patient population). The cytokine concentrations were also analyzed in relation to markers of thyroid humoral immunity, such as circulating anti-thyrotropin (TSH) receptor antibodies (TRAb) and anti-thyroperoxidase antibodies (TPOAb).

\section{Subjects and methods}

We studied 84 GD patients, 74 women and 10 men aged 17-79 years (mean age \pm s.E. $45 \pm 1.0$ years). Patients were divided into two groups; 51 untreated patients, of whom 16 were euthyroid in remission after a previous course of methimazole (MMI) therapy of 336 months' duration and 35 newly diagnosed hyperthyroid, and a group of 33 patients, of whom 18 were euthyroid and 15 were hyperthyroid and had been treated with MMI. Ophthalmopathy was diagnosed by performing a complete eye examination as described previously (23). Patients with signs of soft tissue inflammation, including edema of the lids, chemosis, caruncle edema and conjunctival injection, in addition to progressively increasing proptosis $(>2 \mathrm{~mm})$ were classified as having active TAO (24). After ophthalmological evaluation, 23 of the 51 (45\%) patients not taking MMI and 18 of the $33(54 \%)$ patients on MMI were diagnosed as having active TAO. The ophthalmopathy was absent or clinically inactive in all other patients studied $(n=43)$. We also studied 67 normal subjects, 61 women and 6 men aged 21-70 years (mean age \pm s.E., $48 \pm 1.0$ years) as controls. We gathered information on smoking habits at the time of serum sampling in 72 GD patients and 45 controls. Thirty-one Graves' patients (43\%) and 16 normal subjects $(36 \%)$ were current smokers (10-40 cigarettes daily), whereas non-smokers had either never smoked or had stopped for almost 10 years, with the exception of a woman who had stopped 18 months before testing

Serum IL-6, sIL-6R, TNF- $\alpha$, IL-1 $\beta$ and IL-1Ra concentrations were measured by commercial high sensitivity ELISA, incorporating specific monoclonal antibodies (Quantikine, R\&D Systems, Minneapolis, $\mathrm{MN}$, USA). Assay sensitivity was $0.156 \mathrm{pg} / \mathrm{ml}$ for IL-6, $31.3 \mathrm{pg} / \mathrm{ml}$ for sIL-6R, $0.5 \mathrm{pg} / \mathrm{ml}$ for TNF- $\alpha, 0.125 \mathrm{pg} /$ $\mathrm{ml}$ for $\mathrm{IL}-1 \beta$ and $22 \mathrm{pg} / \mathrm{ml}$ for $\mathrm{IL}-1 \mathrm{Ra}$. Intra- and interassay coefficients of variation were $3.2 \%$ and $3.3 \%$ for IL- 6 , and $8.6 \%$ and $7.3 \%$ for sIL-6R respectively. Intra-assay coefficients of variation for TNF- $\alpha$, IL-1 $\beta$ and IL-1Ra were 3.8, 7.8 and $<5 \%$ respectively. Serum concentrations of TSH, free T4 (FT4) and free T3 (FT3) were measured using commercial kits (Amerlite, Johnson \& Johnson Clinical Diagnostics, Milan, Italy).

Circulating TPOAb were measured by radioimmunometric assay (Dyno-test, Henning, Berlin, Germany) and TRAb by radioreceptor assay (TRAK, Henning, Berlin, Germany). The test was positive for values $>100 \mathrm{U} / \mathrm{ml}$ for TPOAb and for values $>10 \mathrm{U} / \mathrm{l}$ for TRAb.

Values of cytokine concentrations are reported as mean \pm S.E. Statistical analysis was carried out by multivariate ANOVA and Bonferroni's adjusted test for multiple comparisons, automatically applied by a computer program (Systat). The multiplication factor was calculated based on the number of comparisons applied. The logarithm of IL-6 (lnIL-6) values was calculated before performing ANOVA, because of the non-parametric distribution of the data. Age, thyroid hormone and cytokine concentrations were entered in the analysis as continuous variables, whereas smoking and TAO activity parameters were entered as digitomized (yes/no) variables.

\section{Results}

\section{Effect of therapy with MMI}

Serum IL-6, sIL-6R and IL-1Ra concentrations in untreated and treated GD patients and in controls are 
Table 1 Serum cytokine concentrations in Graves' patients and normal subjects.

\begin{tabular}{lc}
\hline & Means \pm S.E.M. \\
\hline Graves' patients & \\
Untreated $(n=51)$ & \\
Age (years) & $44 \pm 2$ \\
IL-6 $(\mathrm{pg} / \mathrm{ml})$ & $3.2 \pm 0.4$ \\
slL-6R $(\mathrm{ng} / \mathrm{ml})$ & $47.4 \pm 2.5$ \\
IL-1Ra $(\mathrm{pg} / \mathrm{ml})$ & $555.1 \pm 32.4$ \\
Treated with methimazole $(n=33)$ & \\
Age (years) & $48 \pm 2$ \\
IL-6 $(\mathrm{pg} / \mathrm{ml})$ & $2.8 \pm 0.3$ \\
slL-6R $(\mathrm{ng} / \mathrm{ml})$ & $36.0 \pm 1.7$ \\
IL-1Ra $(\mathrm{pg} / \mathrm{ml})$ & $660.6 \pm 74.7$ \\
Controls $(n=67)$ & \\
Age $(\mathrm{years})$ & $48 \pm 1$ \\
IL-6 $(\mathrm{pg} / \mathrm{ml})$ & $1.9 \pm 0.2$ \\
slL-6R $(\mathrm{ng} / \mathrm{ml})$ & $40.4 \pm 1.4$ \\
IL-1Ra $(\mathrm{pg} / \mathrm{ml})$ & $553.7 \pm 25.6$ \\
\hline
\end{tabular}

reported in Table 1. By carrying out multivariate analysis in all patients, we found that serum IL-6 concentrations were influenced by age $(P<0.01)$, but not treatment. When compared with controls (Fig. 1), lnIL-6 concentrations, adjusted for age, were significantly higher in untreated patients (0.91 vs 0.33; Bonferroni, $P<0.001)$ and treated patients $(0.75$ vs 0.33 ; Bonferroni, $P<0.006)$. Serum sIL-6R concentrations were significantly affected by treatment $(P=0.001)$; in untreated GD patients they were significantly higher than those of patients on MMI and controls (Fig. 2). Serum IL-1Ra concentrations were not different in GD patients, treated or untreated, when compared with controls (data not shown). Serum concentrations of TNF- $\alpha$ and IL- $1 \beta$ were not measured in patients on MMI.

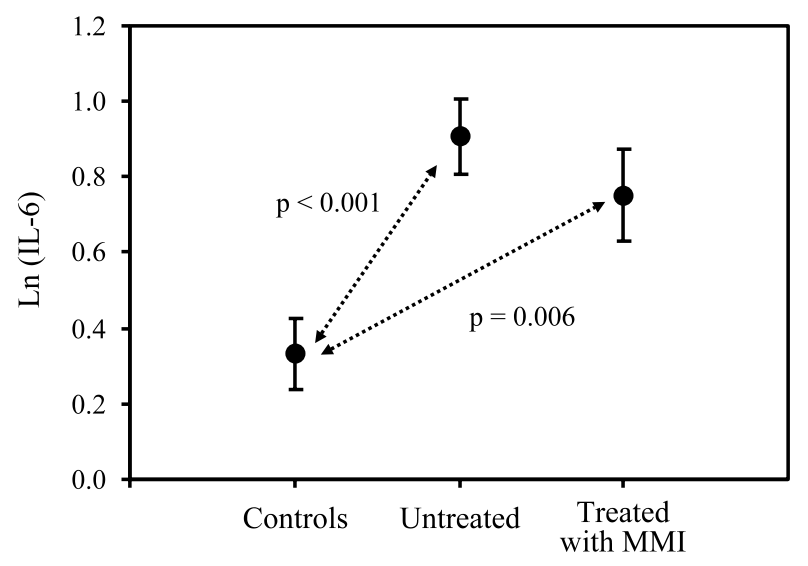

Figure 1 Serum IL-6 concentrations in untreated and treated patients with Graves' disease and normal subjects. Values are expressed as the logarithm of IL-6 concentrations (InIL-6) and are analyzed with Bonferroni test. MMI, methimazole.

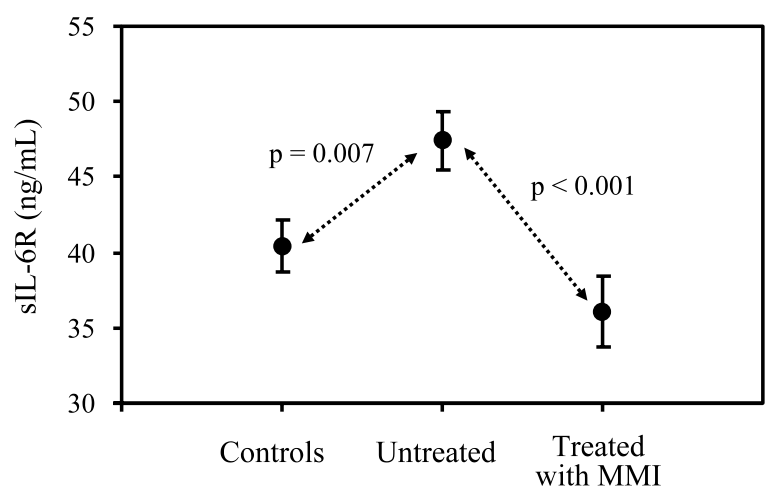

Figure 2 Serum sIL-6R concentrations in untreated and treated patients with Graves' disease and normal subjects. Values are analyzed with Bonferroni test. MMI, methimazole.

\section{Effect of hyperthyroidism and TAO}

Serum IL-6, sIL-6R, IL-1 $\beta$, IL-1Ra and TNF- $\alpha$ concentrations in untreated GD patients with and without active TAO are reported in Table 2. Multivariate analysis in all patients showed that serum IL- 6 concentrations were not influenced by thyroid function, although there was a significant interaction between treatment and the presence of active TAO $(P=0.003)$, with an opposite and spectacular effect of treatment and activity of TAO, as shown in Fig. 3. Serum lnIL-6 concentrations in untreated patients with active TAO were higher than those with inactive TAO (1.18 vs 0.63; Bonferroni, $P=0.04)$ and those of MMI-treated patients with active TAO (1.18 vs 0.57; Bonferroni, $P=0.04$ ).

Serum sIL-6R concentrations in all patients were significantly and independently affected by active TAO $(P<0.05)$ and treatment $(P=0.001$, Fig. 4). In untreated patients we have found a significant interaction between thyroid function and activity of TAO $(P=0.005)$. In hyperthyroid patients with active TAO, serum sIL-6R concentrations were significantly higher

Table 2 Serum cytokine concentrations in untreated Graves' patients with and without active ophthalmopathy.

\begin{tabular}{lc}
\hline & Means \pm S.E.M. \\
\hline Active $(n=23)$ & \\
IL-6 $(\mathrm{pg} / \mathrm{ml})$ & $4.4 \pm 0.7$ \\
slL-6R $(\mathrm{ng} / \mathrm{ml})$ & $53.2 \pm 4.6$ \\
IL-1 $(\mathrm{pg} / \mathrm{ml})$ & $1.8 \pm 0.4$ \\
IL-1Ra $(\mathrm{pg} / \mathrm{ml})$ & $580.8 \pm 39.4$ \\
TNF $(\mathrm{pg} / \mathrm{ml})$ & $5.2 \pm 0.9$ \\
Inactive $(n=28)$ & \\
IL-6 $(\mathrm{pg} / \mathrm{ml})$ & $2.2 \pm 0.3$ \\
slL-6R $(\mathrm{ng} / \mathrm{ml})$ & $42.6 \pm 2.3$ \\
IL-1 $(\mathrm{pg} / \mathrm{ml})$ & $1.5 \pm 0.2$ \\
IL-1Ra $(\mathrm{pg} / \mathrm{ml})$ & $534.3 \pm 49.4$ \\
TNF $(\mathrm{pg} / \mathrm{ml})$ & $4.4 \pm 0.4$ \\
\hline
\end{tabular}




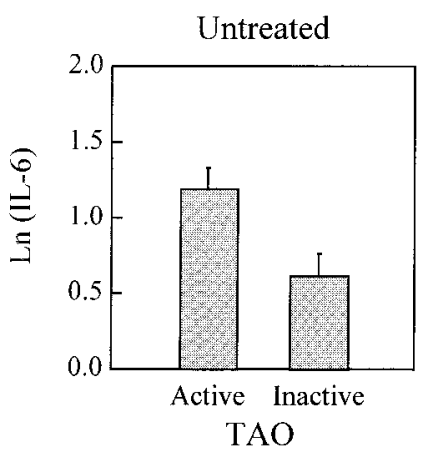

TAO

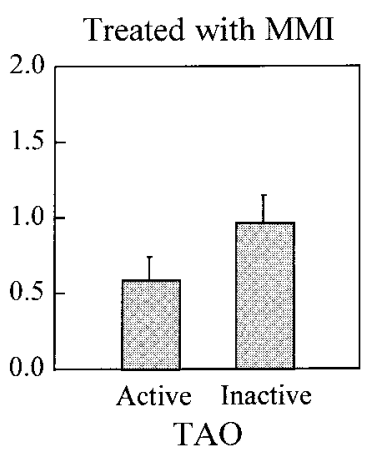

Figure 3 Serum IL-6 concentrations in untreated and treated patients with Graves' disease: interaction between treatment and activity of thyroid-associated ophthalmopathy (TAO). Values are expressed as the logarithm of IL-6 (InIL-6) and analyzed with multivariate ANOVA (interaction: $P=0.003$ ). MMI, methimazole. than those of hyperthyroid patients with inactive TAO $\quad(61.6 \pm 4.1$ vs $41.6 \pm 3.5 \mathrm{ng} / \mathrm{ml}$; Bonferroni, $P=0.003)$ and those of euthyroid patients with active TAO $(37.5 \pm 5.6 \mathrm{ng} / \mathrm{ml} ; P=0.006$, not shown).

In untreated GD patients we did not observe any significant effect of thyroid function or TAO activity on the serum concentrations of TNF- $\alpha$ and IL-1 $\beta$ (not shown). Serum IL-1Ra concentrations were not influenced by the presence of TAO but by a significant interaction of MMI therapy and thyroid function $(P=0.04$, not shown), although the serum IL-1Ra concentrations in hyperthyroid patients on MMI were not significantly higher than those of untreated hyperthyroid patients (Bonferroni, $P=$ n.s.).

\section{Effect of cigarette smoking}

We did not find any effect of smoking on serum IL-6, sIL$6 \mathrm{R}, \mathrm{TNF}-\alpha$, IL-1 $\beta$ and IL-1Ra concentrations. In addition, smoking and the presence of an active TAO did not significantly influence the serum IL-1Ra concentration.

\section{Cytokines and thyroid autoantibodies}

TRAb were measured in the serum of 46 untreated GD patients and detected in 15 of $29(52 \%)$ hyperthyroid and in 5 of $17(29 \%)$ euthyroid patients. TRAb were present in 12 of $22(54 \%)$ patients with active TAO and in 8 of $24(33 \%)$ patients with inactive/absent TAO.
Serum concentrations of IL- 6 , sIL-6R, TNF- $\alpha$ and IL-1 $\beta$ and IL-1Ra were not different in patients with and without TRAb, in relation to either thyroid function, TAO activity or smoking.

TPOAb were detected in the serum of 36 GD patients, 24 of whom were hyperthyroid and 12 euthyroid. Again, we did not find a relationship between the serum concentrations of any of the cytokines and the presence of TPOAb in relation to thyroid function, TAO or smoking.

\section{Discussion}

We have previously reported that hyperthyroid GD patients have increased serum concentrations of IL-6 and of sIL-6R (15), measured by a sensitive ELISA assay, in contrast with the findings of Weetman et al. based on an IL- 6 bioassay (25). In the present study, the measurement of serum concentrations of TNF- $\alpha$, IL- $1 \beta$ and IL-1Ra, in addition to those of IL- 6 and sIL-6R, has provided an insight for a distinct role of inflammatory cytokines in GD. We have observed an increase of IL-6 and sIL-6R concentrations but not of the other proinflammatory cytokines in GD patients. Our findings are in contrast with those of others $(16,17,22)$, who have reported increased serum IL- 6 concentrations in both autoimmune and non-autoimmune hyperthyroid patients, which returned to normal after antithyroid drug treatment. In one of these studies, Çelik et al. (16) suggested that increased TNF- $\alpha$ concentrations in
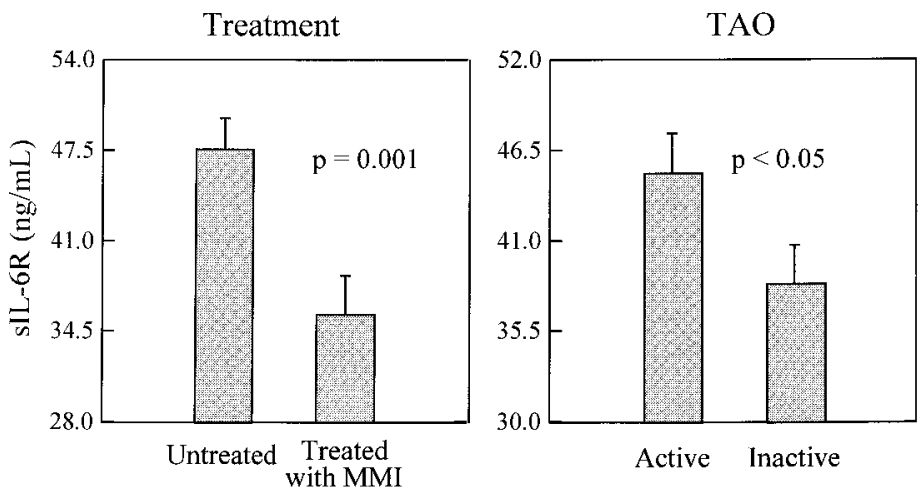

Figure 4 Serum sIL-6R concentrations in patients with Graves' disease: effect of treatment with MMI (methimazole) and of activity of thyroid-associated ophthalmopathy (TAO). Values analyzed with multivariate ANOVA. 
hyperthyroid GD patients were more probably related to thyroid autoimmunity than IL- 6 , as the former did not change with therapy while the latter changed in relation to thyroid function. To date, the role of proinflammatory cytokines in GD remains controversial. Paschke et al. (26) have not found any TNF- $\alpha$ or TNF- $\alpha$ mRNA in thyroid tissue from patients with relapsing GD, by immunohistology or by reverse PCR respectively (despite the presence of macrophages and Tcells in the thyroid infiltrates) and suggested that serum TNF- $\alpha$ concentrations may be low during the chronic phase of GD. Using reverse PCR, Aust et al. (27) recently found high levels of TNF- $\alpha$ mRNA in tissues from patients with Hashimoto's thyroiditis (HT) and thyroid autonomy, but low levels in patients with GD, and suggested that thyroid-derived lymphocytes potentially produce TNF- $\alpha$. Although mRNA for TNF- $\alpha$, IL- $1 \beta$ and IL-6 has also been reported by others in higher concentrations in tissue from GD and HT than from non-toxic goiter (21), the nature of GD is such that local cytokine analysis may be greatly influenced by the course of the disease. Moreover, in a recent paper, Tsatsoulis et al. (28) found moderately increased IL-1 $\beta$ concentrations in hyperthyroid patients with either GD or toxic goiter which increased further after antithyroid therapy. The discrepancies in the results of all these studies may depend on not having considered the effect of antithyroid drug treatment, that somehow modifies the cytokine pattern of GD, before selecting the patients for serological or tissue typing studies.

In this study, as in our previous report (15), we did not observe lower serum IL-6 concentrations in patients treated with MMI. Moreover, we have failed to show a relationship between the differences of IL-6/sIL-6R concentrations and the presence of circulating TRAb or TPOAb, suggesting that the activation of the IL-6 system may be independent of thyroid function and of humoral reactions in the thyroid. A correlation between increased numbers of peripheral T- and B-cells binding IL-6, and serum TRAb activity has been found in hyperthyroid untreated GD patients in a recent study (29), suggesting that IL-6 is involved in both the immunological and the hormonal abnormalities of the disease. Heuer et al. (30) studied the patterns of cytokine mRNA expression in GD, HT and non-autoimmune disorders and observed mainly quantitative differences, i.e. higher levels of cytokines in the autoimmune compared with non-autoimmune thyroids.

Our findings confirm the increase of serum sIL-6R concentrations in active TAO and a significant interaction with thyroid hyperfunction, as we previously and indirectly observed by covariance analysis (15). Molnár \& Balázs (31) recently reported increased serum IL-6 concentrations in hyperthyroid patients with active Graves' ophthalmopathy compared with patients without eye disease, but they observed no difference in euthyroid patients or in patients treated with MMI or radioiodine. It is not clear from their work if it is the presence of TAO or the influence of hyperthyroidism and antithyroid therapy that accounts for the changes on IL-6 concentrations. Other studies on orbital proinflammatory cytokines have shown immunoreactivity for $\gamma$-interferon $(\gamma$-IFN), TNF- $\alpha$ and IL- $1 \beta$ in retroocular fibroblasts (19), whereas cytokine gene expression studies in extraocular muscle samples have detected IL-4 (32) and TNF- $\alpha$ and IL- 6 , but not $\gamma$-IFN (33). Interestingly, we have not been able to find any significant association between the presence of eye disease and changes in the serum concentrations of IL-1 and IL-1Ra, whether the patients had active or inactive disease and were smokers or not. This is in contrast with the in vitro findings recently reported by Tan et al. (18) and those by Hofbauer et al. (20) in Graves' patients undergoing orbital radiotherapy for severe TAO. We cannot rule out that even in those studies the patients' selection, including perhaps patients on antithyroid medications together with others untreated, may account for the discrepant results. Although it is well accepted that cigarette smoking has a detrimental effect on TAO, our findings do not confirm the effect on serum IL-1/IL-1Ra concentrations.

Although cytokines detected in the peripheral circulation may differ from those produced in the tissue infiltrates, our work suggests that the increased serum IL-6/sIL-6R concentrations in patients with active TAO may not derive from the activation of humoral reactions in the thyroid. Of the possible tissues in which these cytokines are produced, we think that the orbit may be a plausible site. On the other hand, as we have shown that these changes are influenced by many factors, such as thyroid status and therapy, we do not believe that the measurement of these cytokines in the serum is useful for the diagnosis of active TAO.

\section{Acknowledgements}

This work was supported by Grants 93.00413.CT04, 95.00877.CT04, 93.00405.CT04 and 95.00940.CT04 of the Consiglio Nazionale delle Ricerche (Rome, Italy) and 'Fisiopatologia Endocrina' of the Ministero dell' Università e Ricerca Scientifica 40\% (Rome, Italy). $\mathrm{R}$ Minelli is a recipient of a fellowship from Associazione Volontaria Promozione Ricerca Tumori (A.VO.PRO. RI.T.), Parma, Italy. Dr Mario Salvi is Visiting Adjunct Professor, Department of Medicine, McGill University, Montreal, Canada. This paper was presented in part at the 24th Annual Meeting of the European Thyroid Association, Munich, Germany, 30 August-3 September, 1997.

\section{References}

1 Abbas AK, Lichtman AH \& Pober JS (Eds). Cytokines. In Cellular and Molecular Immunology, ch 11, pp 229-236. Philadelphia, PA, USA: WB Saunders Company, 1991.

2 Mackiewicz A, Schooltink H, Heinrich PC \& Rose-John S. 
Complex of soluble human IL-6-receptor/IL-6 up-regulates expression of acute-phase proteins. Journal of Immunology 1992 149 2021-2027.

3 Barton BE. IL-6: Insights into novel biological activities. Clinical Immunology and Immunopathology 199785 16-20.

4 Male D, Cooke A, Owen M, Trowsdale J \& Champion B (Eds). Cytokines and chemokines. In Advanced Immunology, edn 3, ch 10 , pp 10.1-10.14. London, UK: Mosby, 1996.

5 Metcalfe RA \& Weetman AP. Stimulation of extraocular muscle fibroblasts by cytokines and hypoxia: possible role in thyroidassociated ophthalmopathy. Clinical Endocrinology $19944067-$ 72.

6 Kuschner WG, D’Alessandro A, Wong H \& Blanc PD. Dosedependent cigarette smoking-related inflammatory responses in healthy adults. European Respiratory Journal 19969 1989-1994.

7 Mikuniya T, Nagai S, Shimoji T, Takeuchi M, Morita K, Mio T et al. Quantitative evaluation of the IL-1 beta and IL-1 receptor antagonist obtained from BALF macrophages in patients with interstitial lung disease. Sarcoidosis Vasculitis and Diffuse Lung Diseases 199714 39-45.

8 Mol MJ, de Rijke YB, Demacker PN \& Stalenhoef AF. Plasma levels of lipid and cholesterol oxidation products and cytokines in diabetes mellitus and cigarette smoking: effects of vitamin $\mathrm{E}$ treatment. Atherosclerosis 1997129 169-176.

9 Mendall MA, Patel P, Asante M, Ballam L, Strachan DP, Camm $\mathrm{AJ}$ et al. Relation of serum cytokine concentrations to cardiovascular risk factors and coronary heart disease. Heart $199778273-277$.

10 Pessina GP, Paulesu L, Corradeschi F, Aldinucci C, Luzzi E \& Bocci V. Pulmonary catabolism of interleukin- 6 evaluated by lung perfusion of normal and smoker rats. Journal of Pharmacy and Pharmacology 199648 1063-1067.

11 McCrea KA, Ensor JA, Nall K, Bleecker ER \& Hasday JD. Altered cytokine regulation in the lungs of cigarette smokers. American Journal of Respiratory and Critical Care Medicine 1994 $150696-703$.

12 Soliman DM \& Twigg HL. Cigarette smoking decreases bioactive interleukin-6 secretion by alveolar macrophages. American Journal of Physiology 1992263 L471-L478.

13 Bartalena L, Grasso L, Brogioni S, Aghini-Lombardi F, Braverman LE \& Martino E. Serum interleukin- 6 in amiodarone-induced thyrotoxicosis. Journal of Clinical Endocrinology and Metabolism 199478 423-427.

14 Bartalena L, Brogioni S, Grasso L, Rago T, Vitti P, Pinchera A et al. Interleukin-6: A marker of thyroid-destructive processes? Journal of Clinical Endocrinology and Metabolism 199479 14241427.

15 Salvi M, Girasole G, Pedrazzoni M, Passeri M, Giuliani N, Minelli $\mathrm{R}$ et al. Increased serum concentrations of interleukin-6 (IL-6) and soluble IL-6 receptor in patients with Graves' disease. Journal of Clinical Endocrinology and Metabolism 199681 2976-2979.

16 Celik I, Akalin S \& Erbas T. Serum levels of interleukin 6 and tumor necrosis factor- $\alpha$ in hyperthyroid patients before and after propylthiouracil treatment. European Journal of Endocrinology $1995132668-672$.

17 Lakatos P, Foldes J, Horvath C, Kiss L, Tatrai A, Takacs I et al. Serum interleukin-6 and bone metabolism in patients with thyroid function disorders. Journal of Clinical Endocrinology and Metabolism 199782 78-81.

18 Tan GH, Dutton CM \& Bahn RS. Interleukin-1 (IL-1) receptor antagonist and soluble IL-1 receptor inhibit IL-1induced glycosaminoglycan production in cultured human orbital fibroblasts from patients with Graves' ophthalmopathy. Journal of Clinical Endocrinology and Metabolism 1996 $81449-452$
19 Heufelder AE \& Bahn RS. Detection and localization of cytokine immunoreactivity in retro-ocular connective tissue in Graves' ophthalmopathy. European Journal of Clinical Investigation 199323 $10-17$.

20 Hofbauer LC, Mühlberg T, König A, Heufelder G, Schworm H-D \& Heufelder AE. Soluble interleukin- $\beta$ receptor antagonist serum levels in smokers and nonsmokers with Graves' ophthalmopathy undergoing orbital radiotherapy. Journal of Clinical Endocrinology and Metabolism 199782 2244-2247.

21 Feldmann M, Brennan FM, Chantry D, Haworth C, Turner M, Katsikis $\mathrm{P}$ et al. Cytokine assays: Role in evaluation of the pathogenesis of autoimmunity. Immunological Reviews 1991119 105-123.

22 Siddiqi A, Monson JP, Wood DF, Besser GM \& Burrin JM. Serum cytokines in thyrotoxicosis. Journal of Clinical Endocrinology and Metabolism 199984 435-439.

23 Salvi M, Spaggiari E, Neri F, Macaluso C, Gardini E, Ferrozzi F et al. The study of visual evoked potentials in patients with thyroidassociated ophthalmopathy identifies asymptomatic optic nerve involvement. Journal of Clinical Endocrinology and Metabolism 1997 82 1027-1030.

24 Mourits MP, Koorneef L, Wiersinga WM, Prummel MF, Berghout A, VD \& Gaag R. Clinical criteria for the assessment of disease activity in Graves' ophthalmopathy: a novel approach. British Journal of Ophthalmology 198973 639-644.

25 Weetman AP, Bright-Thomas R \& Freeman M. Regulation of interleukin-6 release by human thyrocytes. Journal of Endocrinology 1990127 357-361.

26 Paschke R, Kist A, Jänicke R, Eck T, Velu T \& Usadel KH. Lack of intrathyroidal tumor necrosis factor $\alpha$ in Graves' disease. Journal of Clinical Endocrinology and Metabolism 199376 97-102.

27 Aust G, Heuer M, Laue S, Lehmann I, Hofmann A, Heldin N-E et al. Expression of tumor necrosis factor-alpha (TNF- $\alpha$ ) mRNA and protein in pathological thyroid tissue and carcinoma cell lines. Clinical and Experimental Immunology $1996105148-$ 154.

28 Tsatsoulis A, Vlachoyiannopoulos PG, Dalekos GN, Johnson EO \& Moutsopoulos HM. Increased serum interleukin-1 $\beta$ during treatment of hyperthyroidism with antithyroid drugs. European Journal of Clinical Investigation 199525 654-658.

29 Corrales JJ, Orfao A, Lopez A, Mories MT, Miralles JM \& Ciudad J. Analysis of IL-2 and IL-6 binding to peripheral blood lymphocytes in Graves' disease: Relationship with disease activity. Cytometry $199730118-123$.

30 Heuer M, Aust G, Ode-Hakim S \& Scherbaum WA. Different cytokine mRNA profiles in Graves' disease, Hashimoto's thyroiditis, and nonautoimmune thyroid disorders determined by quantitative reverse transcriptase polymerase chain reaction (RT-PCR). Thyroid 19966 97-106.

31 Molnár I \& Balázs C. High circulating IL-6 level in Graves' ophthalmopathy. Autoimmunity 199725 91-96.

32 McLachlan SM, Prummel MF \& Rapoport B. Cell-mediated or humoral immunity in Graves' ophthalmopathy? Profiles of T-cell cytokines amplified by polymerase chain reaction from orbital tissue. Journal of Clinical Endocrinology and Metabolism 199478 1070-1074.

33 Pappa A, Calder V, Ajjan R, Fells P, Ludgate M, Weetman AP et al. Analysis of extraocular muscle-infiltrating $\mathrm{T}$ cells in thyroidassociated ophthalmopathy (TAO). Clinical and Experimental Immunology 1997109 362-369.

Received 7 November 1999

Accepted 30 March 2000 